\title{
APPLICATION OF BAYESIAN NETWORK AS A TOOL FOR COASTAL FLOODING IMPACT PREDICTION AT VARNA BAY (BULGARIA, WESTERN BLACK SEA)
}

\author{
Nikolay Valchev ${ }^{1}$, Petya Eftimova ${ }^{1}$, Nataliya Andreeva ${ }^{1}$ and Bogdan Prodanov ${ }^{1}$
}

\begin{abstract}
Storms and related disasters are one of the most important phenomena producing coastal hazards and endangering human life and occupation. While coastal response to extreme forcing conditions can be evaluated using numerical models, there is increasing need for less computationally expensive probability tools that can quickly produce results thus contributing to more effective coastal risk management. A possible response to this demand is a Bayesian Network, which relates near-shore storm conditions to their onshore flood potential and ultimately translates them to relevant impact (consequences) expressed as damage to various receptor groups. Bayesian Network can constitute a module in an early warning system or can be used as a planning tool to evaluate the long-term vulnerability due to multiple coastal hazards, under various climate-related scenarios. The present study describes the application of a Bayesian Network for Varna Bay building on developments made in the framework of the RISC-KIT (ResilienceIncreasing Strategies for Coasts - toolKIT) project. Moreover, several alternatives involving disaster risk reduction measures were examined both in present and future climate conditions. It was found that the analysis of results through the prism of the Bayesian Network provides a useful insight of the problems at the study site making it a reliable coastal impact prediction tool.
\end{abstract}

Keywords: coastal storms; coastal hazards; flooding; impact assessment; Bayesian network

\section{INTRODUCTION}

Coastal zone is among the fastest evolving areas worldwide. Ever increasing population inhabiting coastal settlements (Collet and Engelbert 2013) often develops conflicting economic and societal activities. The existing imbalance between the expansion of these activities, on one hand, and the potential to accommodate them in a sustainable manner, on the other, becomes a critical problem. Concurrently, coasts are affected by various hydro-meteorological phenomena such as storm surges, heavy seas and strong winds (e.g. Kunz et al. 2013, Bertin et al. 2014), all the more that, risks are projected to increase globally, due to growing populations and assets, accelerated sea level rise and potential increases in storminess (both tropical and extra-tropical) (Hallegatte et al., 2013). These realities emphasize the ongoing need for effective coastal risk management.

Western Black Sea has experienced extreme historical storms hitting from the eastern half as the main sources of hazard are high storm surges, large waves and coastal erosion (Trifonova et al. 2012, Valchev et al. 2012). One of the severest storms ever occurred in February 1979, during which heavy persistent north-eastern winds gave rise to substantial surge and large waves. The resultant flooding and erosion caused significant damages to beaches, ports, tourist and private property along the entire Black Sea coast. Particular damages were reported along the breakwater of Port of Varna wall and adjacent infrastructure (Stakev 1980, Andreeva et al. 2011). Although, a slight reduction of storminess has been observed for the past decade (Valchev et al. 2012), the impact of a recent extreme storm that took place in February 2012 (Fig. 1) has shown that lessening of vulnerability to storms in the western Black Sea is unlike and the society should take into consideration marine hazards while planning strategies for coastal development and disaster mitigation activities. This implies elaboration of tools capable of quick prediction of the impact of high-energy low-probability hydro-meteorological events and testing the feasibility of various disaster risk reduction strategies.

One such tool is Bayesian Network (BN), which is a probabilistic graphical model representing a set of random variables and their conditional dependencies. The principles, models and methods of Bayesian forecasting and time series analysis have been developed extensively during the latest decades. This development has involved thorough investigation of mathematical and statistical aspects of forecasting models and related techniques. They were subsequently applied in a variety of areas in commercial, industrial, scientific, and socio-economic fields. Much of the technical development has been driven by the needs of forecasting practitioners, applied researchers and stakeholders. As a result, there presently exists a relatively complete statistical and mathematical framework (West and Harrison 1997).

\footnotetext{
${ }^{1}$ Coastal Zone Dynamics Department, Institute of Oceanology - Bulgarian Academy of Sciences, 40 Parvi May Blvd., Varna, 9003, Bulgaria, E-mail: valchev@io-bas.bg
} 
In terms of coastal science, a BN could describe the probabilistic relationships between off-shore hydraulic conditions, geomorphic settings, hazard and impact. It can constitute a module in a forecasting and/or early warning systems but also can be used as a consistent ex-ante planning tool to evaluate the long-term vulnerability due to multiple coastal hazards, under various climate-related scenarios. Development of such innovative tool was one of major goals of the RISC-KIT project (van Dongeren et al. 2016).
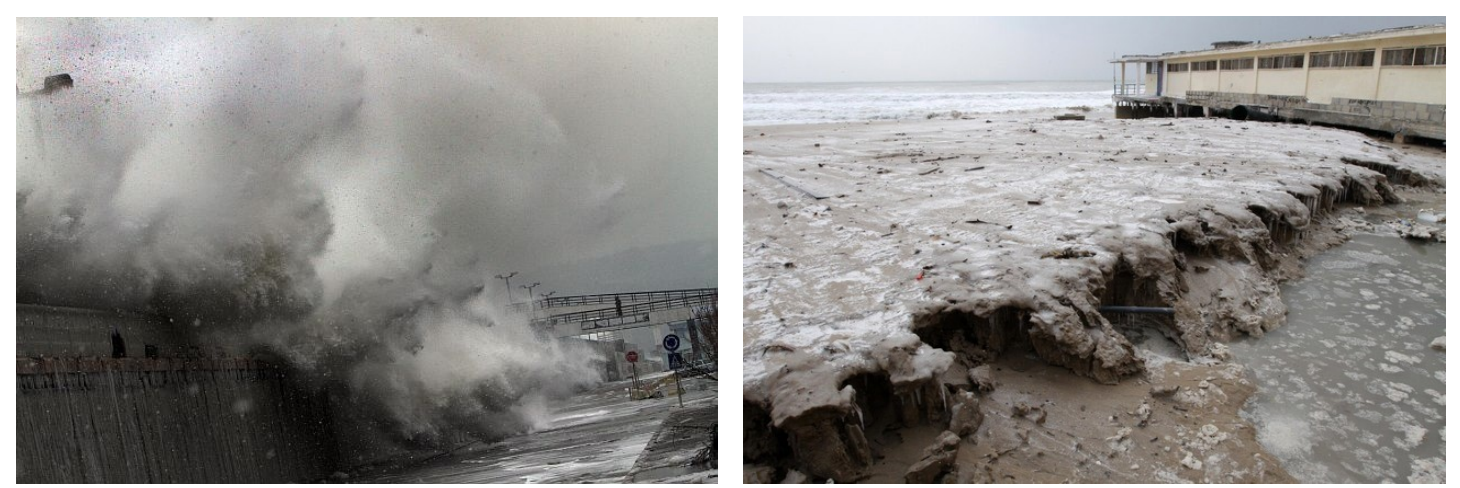

Figure 1. Severe storm damage: large waves overtopping the breakwater of Port of Varna (left) and flooding of Varna beach (right) during the storm of February 2012 (Source: http://dariknews.bg)

The proposed study describes the set-up of such network for Varna Bay (Bulgaria, Western Black Sea) building on the work of Jaeger et al. (2017) who design a decision support system based on predictive capabilities of the BN. For different extreme event scenarios, the BN can give instantaneous predictions of percentages of affected receptors in terms of the hazards experienced and their impacts in real-time. Moreover, the BN can show the effects of potential disaster risk reduction (DRR) measures.

\section{STUDY SITE}

The study site is part of Varna regional coastline (Bulgaria), which is located on the western Black Sea. The Black Sea is an elliptical semi-closed basin of weak tides (about $8 \mathrm{~cm}$ ) with a complex orography located in South-eastern Europe. Varna regional coastline is approximately $70 \mathrm{~km}$-long and includes Varna Bay, which is an open bay stretching from cape St. George to the north to cape Galata to the south (Fig. 2).Its northern arm is entirely protected by coastal defense structures - rocky revetments, groynes and jetties - that resulted in formation of several beaches. The most inner part of Varna Bay holds the largest transport and port agglomeration industrial complex in Bulgaria. Another important regional economic activity is tourism presented by large seaside resorts, as well as small restaurants, beach bars, shops, sport and leisure facilities scattered along the coastline. Varna is the only coastal city in Bulgaria that marks a population growth of $2.8 \%$ (NSI 2011).

The selected hotspot - a highly vulnerable coastal sector according to Valchev et al. (2016) includes Varna beach and the breakwater of Port of Varna (herein referred to as port wall) (Fig. 2). Varna beach is a $1.2 \mathrm{~km}$-long exposed to ESE sand body of variable width - from $5 \mathrm{~m}$ in the most northern to $110 \mathrm{~m}$ in the most southern part. It is backed by a promenade followed farther inland by 10 to $18 \mathrm{~m}$-high cliff and is bordered by a Y-head groyne to the north and by the port wall to the south. Beach slope varies between 0.09 and 0.18 and sediment grain size - between 0.28 and $0.81 \mathrm{~mm}$. The port wall is a part of the port agglomeration industrial complex. It is a $1.18 \mathrm{~km}$-long concrete structure with maximum height of $7.2 \mathrm{~m}$. The port wall embankment consists of rocks and tetrapods.

\section{DATA AND METHODS}

A Bayesian network can be used as a complementary probabilistic tool in an impact oriented coastal early warning system (EWS) serving as a surrogate for a process-based coastal morphodynamic model or as a tool for direct impact assessment. BN consists of nodes and arcs, in which the nodes represent the variables of interest and the arcs indicate the conditional dependencies between them (Pearl and Russel 1988). After the set-up, the network can be trained with a dataset, which may consist of observations or of synthetic numerical model results. In the present application the BN was trained with the outcome of a process-based numerical model, which is used to transform a variety of offshore hydraulic boundary conditions (water levels, wave heights and periods, etc.) at about $15 \mathrm{~m}$ depth to onshore hydrodynamic hazards (water depths). Then, the calculated hazard intensities were translated 
into impact on the coast using regional depth-damage curves. The combination of the hydraulic boundary conditions, onshore hazard and corresponding impact forms the dataset that trains the BN. Once the $\mathrm{BN}$ is trained it can be conditioned with an observation, or prediction, of the boundary conditions to give an instantaneous prediction of onshore hazards and resulting impact on different receptor groups.

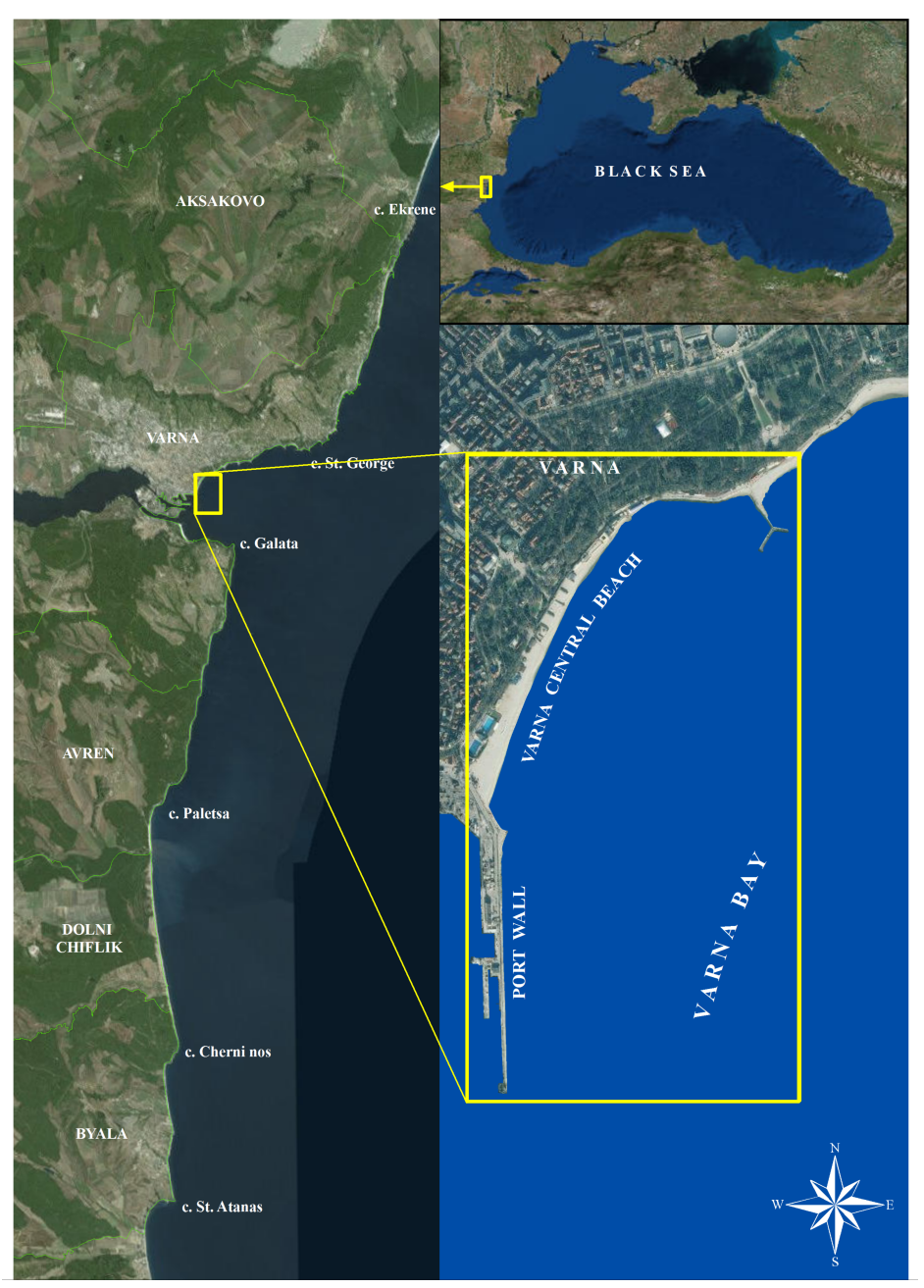

Figure 2. Schematic map of the study site at regional level and hotspot (port wall and Varna beach).

Accordingly, the method involves: determination of a range of hydraulic boundary conditions derived from statistical analysis of numerical hindcast data; performing simulations with a processbased model in order to obtain gridded fields of onshore hazards; set-up of a sufficiently complex BN capable of representing the relations between variables, training of BN and quantification of the coastal impact in terms of relative damage. This is done not only for boundary conditions representative for the present storm climate but also for possible climate change scenarios. Furthermore, the effect of a couple of DRR measures on the onshore hazards and eventually on the degree of impact was investigated.

\section{Compilation of synthetic dataset}

The first step is to obtain a large enough dataset, from which extreme conditions can be derived to train the BN. As it is often the case at any site, there are no long-term observations in Varna Bay. Therefore, main data source was a wave hindcast dataset spanning 63-year period (1949-2012) (Valchev et al. 2012). In compliance with thresholds set in Valchev et al. (2016), more than 140 individual events were identified each represented by maximum significant wave height $\left(\mathrm{H}_{\mathrm{s}}\right)$, corresponding peak wave period $\left(\mathrm{T}_{\mathrm{p}}\right)$, mean wave direction and storm duration. As for peak surge level (h), the historic component of data originating from another modeling study (Vousdoukas et al. 2016) was considered. This approach was preferred for consistency reasons as data from the same source was used to quantify the effect of climate change (CC) according to scenario RCP8.5, horizon 2060. 
Representative Concentration Pathways (RCPs) are four greenhouse gas concentration trajectories adopted by the IPCC in its fifth Assessment Report in 2014 (Moss et al. 2014). Among those RCP8.5 is regarded to as the most pessimistic one with respect to global mean temperature and mean sea level rise. Return level of 100 years was set as upper limit for both historic and projected mean sea level values.

However, hydraulic parameters also show a time variation over the course of a storm event that should be accounted for. Valchev et al. (2012) reported that the typical regional extreme storms consist of three phases: quite short growth phase, a more substantial full development phase and decay, which is the longest one. Of those, the second phase is the most important one since it is expected that coastal hazards would reach their maximum intensity and respectively extent within this time-span.

Thus, building on the knowledge of historic storms in terms of ranges of main hydraulic parameters' variability a large number of synthetic events were formed. The assumption that the major impact occurs during the most energetic part of the storm allowed us to set the synthetic events' duration equal to the second phase one. Such approach is in favor of the computational efficacy.

\section{Onshore hazard modelling}

A process-based model is used to transform hydraulic boundary conditions to onshore flooding hazards. In the current application, 2DH morphodynamic model XBeach (Roelvink at al. 2009) is selected for this purpose because it has been extensively validated for simulating coastal processes over complex 2D bathymetry (Van Thiel de Vries 2009, McCall et al. 2010, Lindemer et al. 2010). It is implemented in 'surfbeat' mode, which includes run-up and run-down of long waves (swash), and uses morphological acceleration ("morfac") factor of 10, on a Cartesian curvilinear grid consisting of $180 \times 78$ cells with variable cross-shore $(1 \mathrm{~m}$ at the beach face and $30 \mathrm{~m}$ off-shore $)$ and long-shore (from $9 \mathrm{~m}$ to $68 \mathrm{~m} \mathrm{NE}$ to $\mathrm{SW}$ along the hotspot) resolution. The hard structures located within the hotspot area are presented as non-erodible layer. Beach sediments are defined as a single sediment fraction with $\mathrm{D}_{50}=0.3 \mathrm{~mm}$ and $\mathrm{D}_{90}=0.4 \mathrm{~mm}$.

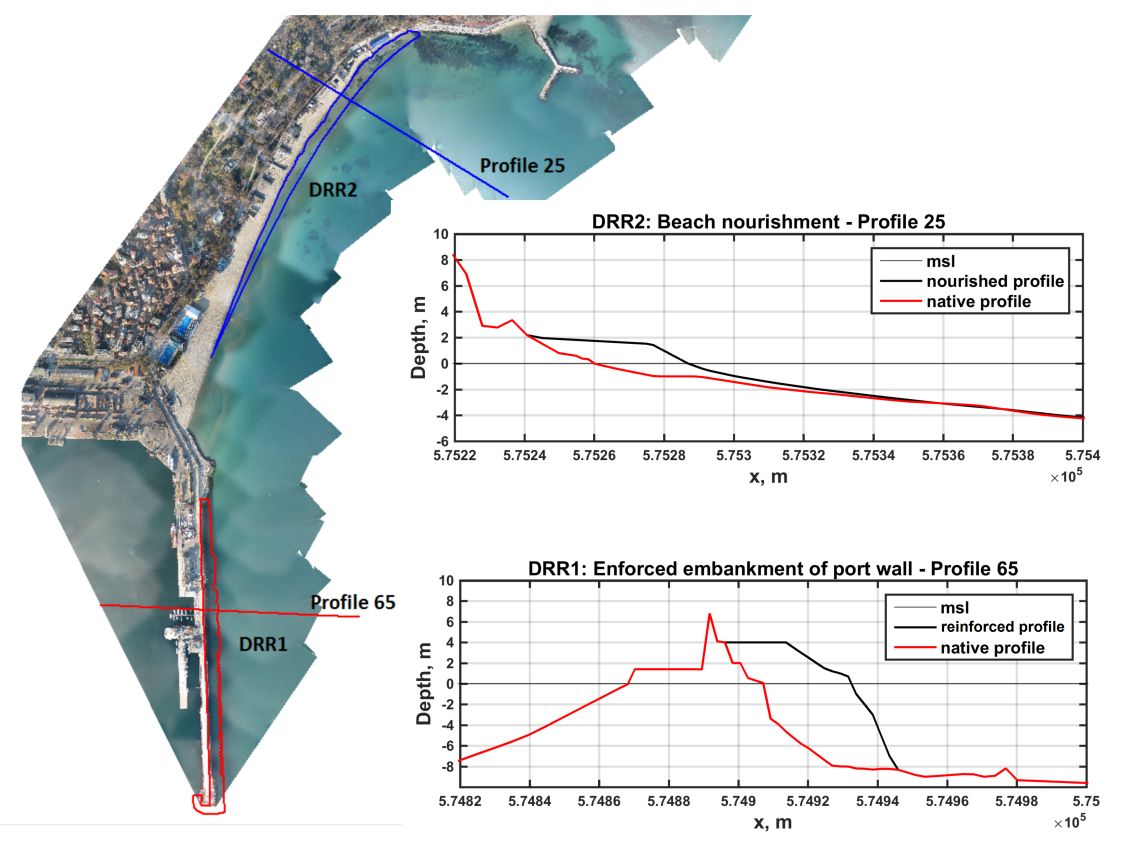

Figure 3. Map indicating position of the proposed hazard influencing DRR measures with display of representative cross-shore profiles for each measure.

In addition, XBeach is the last model in a coastal forecasting system modeling train, which also includes Delft3D models implemented on three nested grid domains able to downscale global atmospheric conditions to the hotspot location (Valchev et al. 2017). The model performance with respect to prediction of the flooding is assessed as very good (Eftimova et al. 2012), though in certain conditions it tends to underestimate the wave run-up but in reasonable limits (Valchev et al. 2017). 


\section{Proposed DRR measures}

In view of problems related to coastal flooding, two structural hazard influencing structural DRR measures were proposed (Fig. 3).

\section{- DRR1: Reinforced embankment of Varna port wall}

This DRR measure is proposed in accordance with a current project for reinforcement of port wall embankment coordinated by Bulgarian Ports Infrastructure Company - Varna. The project is in initial phase of implementation and plans to fortify the embankment with rocks and tetrapods to form a $14 \mathrm{~m}$ long terrace followed by 1:2 seaward slope. The facility will be extended seaward with $19 \div 32 \mathrm{~m}$ along the port wall (Fig. 4).
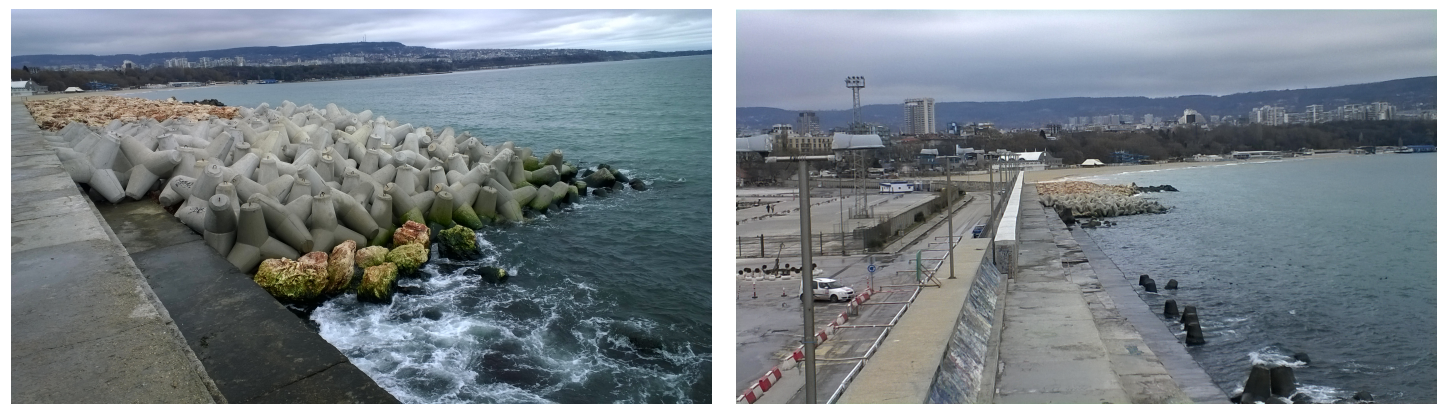

Figure 4. View of the initial stage of the port wall reinforcement.

\section{- DRR2: Varna central beach nourishment}

This DRR measure is applied in the northern part of Varna central beach as it is the most vulnerable to coastal hazards. Fig. 5 shows condition of the beach in 2013 after a couple of heavy storm seasons and proves the need for implementation of similar measure. The native beach face slopes vary southward from 0.10 to 0.19 as well as $\mathrm{D}_{50}$ - from 0.28 to $0.81 \mathrm{~mm}$ (according to data measured in 2015). The nourishment project foresees widening of the beach up to $40 \mathrm{~m}$ in the most northern, as the area of gained sub-aerial beach would be $2.45 \times 10^{-2} \mathrm{~km}^{2}$ (Fig. 3). The sub-areal beach is nourished up to $1.5 \mathrm{~m}$ height assuming beach face slope of 0.12 , which is representative for the area subjected to nourishment. The bathymetry is prepared following the approach described in Dean et al. (2008) using Dean's equilibrium profile formula (Dean 1977) for sediments with $\mathrm{D}_{50}=0.5 \mathrm{~mm}$ up to the closure depth of $8.9 \mathrm{~m}$. The total nourished sand volume is $119.335 \mathrm{~m}^{3}$.
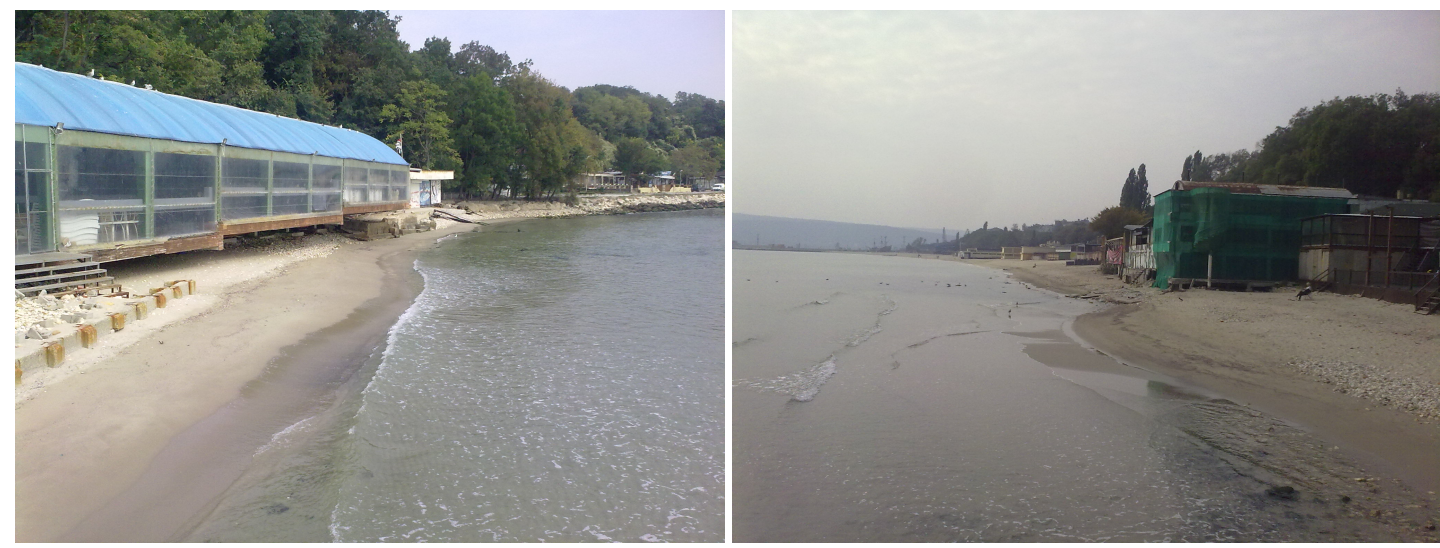

Figure 5. Condition of northern part of Varna beach after a couple of heavy storm seasons (October 2013).

\section{Bayesian Network}

In the present case $\mathrm{BN}$ is used to estimate flooding hazard in the coastal zone, which is determined by local geomorphic setting and hydraulic boundary conditions, and, what is more, to translate the hazard intensities into impact on identified groups of receptors. By definition, a BN is a computational tool used to describe a system in a probabilistic manner. The relation between the variables comes from prior knowledge about the system. A BN driven prediction is possible by updating the network with an 
observation or expected state associated with an event. The BN then uses Bayes' rule to update the likeliness of dependent variables in the network.

Thus, setting up a BN consists of following steps: set up the structure by identifying the variables that need to be considered in order to achieve the desired detail of prediction as well as the dependencies between them, discretize each node into bins, and train the network with a dataset. In this paper, the BN was structured with nodes accounting for receptors (locations), boundary conditions, hazard intensity and impact. Depth-damage (or susceptibility) curves (Dimitrov et al. 2013) were used to translate hazard to impact (consequences). For each depth-damage curve five level of vulnerability (relative damage) were defined: very low, low, moderate, high and very high. Furthermore, BN was configured to explore present and projected storm climate as well as the effect of hazard influencing DRR measures. The software used to create the BN is GeNIe version 2.0, obtained from Decision System Laboratory, University of Pittsburgh (http://www.dslpitt.org). More details on assumptions and modeling choices with regard to the BN in use can be found in Jaeger at al. (2017).

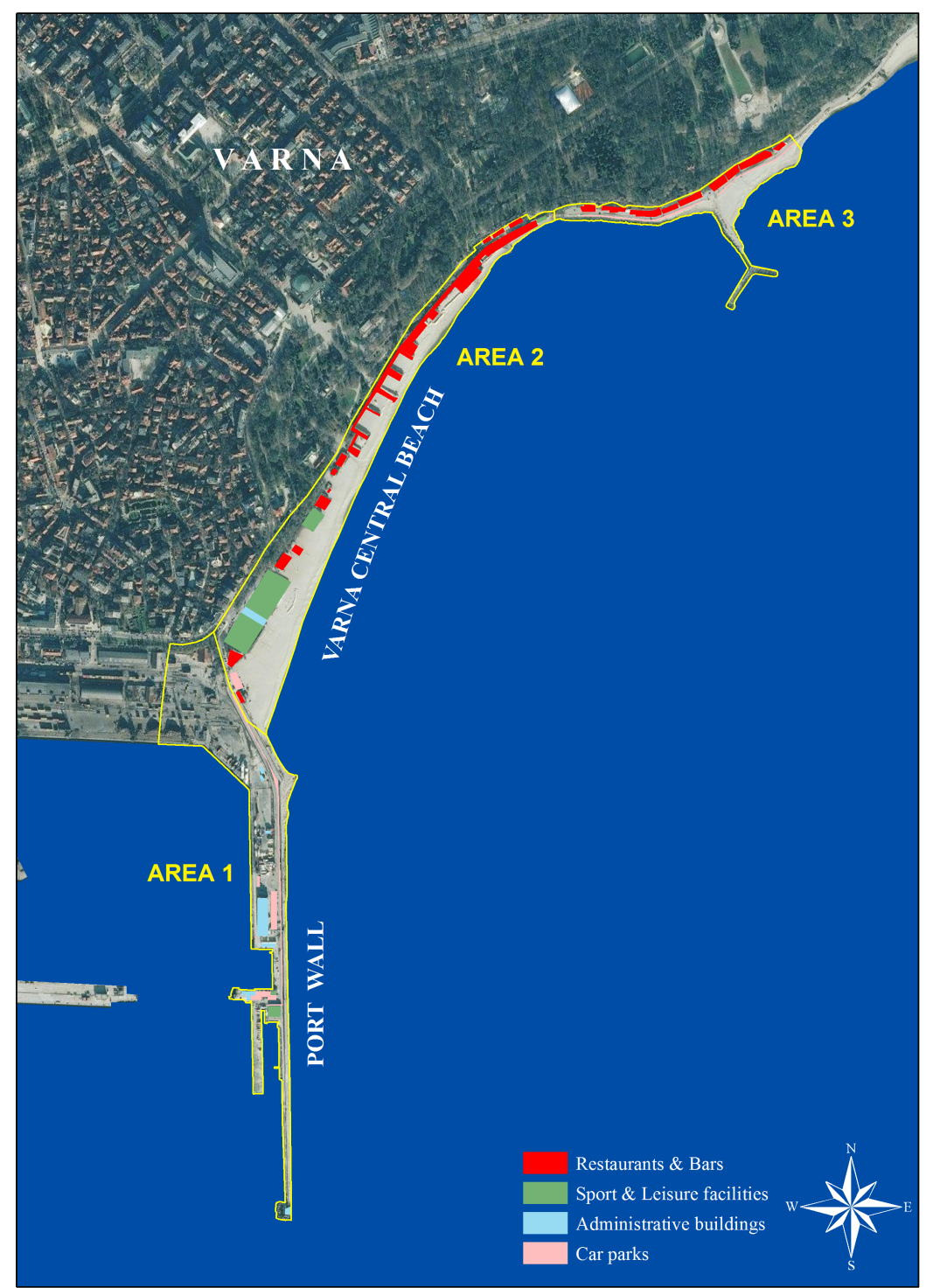

Figure 6. Schematic map of receptors' location within the hotspot Da se obozna4i Area 1, 2, 3 


\section{IMPLEMENTATION OF BAYESIAN NETWORK}

\section{Areas and receptors}

For the purposes of $\mathrm{BN}$ modeling the hotspot was divided into three areas. The first one comprises the port wall and adjacent facilities, the second one includes Varna central beach, while the last one spreads over the rest of the site protected by revetment where a Y-head groyne is located with exposed part of the promenade running in the rear (Fig. 6).

Receptors taken into account are grouped as follows (Fig. 6):

- $\quad$ R1: Restaurants \& Bars: beach restaurants and bars (38 receptors);

- $\quad$ R2: Sport \& Leisure facilities: yacht clubs, surf school, pools, water slide, yacht equipment shops (6 receptors);

- R3: Administrative buildings (3 receptors);

- R4: Car parks (7 receptors).

R1 are located in Area 2 and 3, R2 and R3 - in Area 1 and 2, while R4 are spread across all areas. In addition, DRR1 has effect predominantly on Area 1, whereas DRR2 - on Area 2. Receptors are mapped using a high-resolution digital elevation model (DEM) originating form an ortophotogrametric digital surface model (Valchev et al. 2106).

\section{Synthetic events and training data}

As mentioned above, synthetic events (SE) were formed building on the knowledge of historic coastal storms. Two primary parameters - peak surge level and maximum significant wave height- were used as boundary conditions. Peak surge level varies between $0.3 \mathrm{~m}$ to $0.9 \mathrm{~m}$, while $\mathrm{H}_{\mathrm{s}}$ - between $2.0 \mathrm{~m}$ and $4.5 \mathrm{~m}$. Peak wave period was introduced as a concomitant to $\mathrm{H}_{\mathrm{s}}$. Since a range of $\mathrm{T}_{\mathrm{p}}$ corresponds to a given $\mathrm{H}_{\mathrm{s}}$ storm maximum, the average of all $\mathrm{T}_{\mathrm{p}}$ values was paired with it. Those three parameters form a 2D matrix shown in Table 1. Furthermore, mean wave direction and storm (maximum development phase) duration were introduced as secondary parameters, providing a greater level of variability to the pair of primary ones. Four directional bins were considered: $80^{\circ} \div 90^{\circ}, 90^{\circ} \div 100^{\circ}, 100^{\circ} \div 110^{\circ}$, as well as four durations: $6,10,16$ and $24 \mathrm{~h}$.

The boundary conditions matrix expands with one raw to account for CC scenario (Table 1). This does not concern $\mathrm{h}$ since no change is foreseen for the surge component of total water level. The properties that undergo $\mathrm{CC}$ are the relative mean sea level as projected rise in the studied region is $0.28 \mathrm{~m}$ (Vousdoukas et al. 2016) and $\mathrm{H}_{\mathrm{s}}$. In order to incorporate the sea level rise in the modeling strategy the initial bathymetry was lowered with the mentioned value, thus modifying the site geomorphic setting.

\begin{tabular}{|c|c|c|c|c|c|c|}
\hline \multirow{3}{*}{$\mathrm{H}_{\mathrm{s}}[\mathrm{m}]$} & \multirow{3}{*}{$\mathrm{T}_{\mathrm{p}}[\mathrm{s}]$} & \multirow{2}{*}{\multicolumn{5}{|c|}{$\begin{array}{c}\mathrm{h}[\mathrm{m}] \\
\mathrm{h}+0.28[\mathrm{~m}]\end{array}$}} \\
\hline & & & & & & \\
\hline & & 0.3 & 0.5 & 0.7 & 0.8 & 0.9 \\
\hline 2.0 & 8.2 & 12 & 12 & 12 & 12 & 12 \\
\hline 2.5 & 8.6 & 12 & 12 & 12 & 12 & 12 \\
\hline 3.0 & 9.2 & 8 & 8 & 8 & 8 & 8 \\
\hline 3.5 & 9.9 & 8 & 8 & 8 & 8 & 8 \\
\hline 4.0 & 10.2 & 3 & 3 & 3 & 3 & 3 \\
\hline 4.5 & 10.7 & 3 & 3 & 3 & 3 & 3 \\
\hline 4.8 & 11.0 & 3 & 3 & 3 & 3 & 3 \\
\hline
\end{tabular}

Combinations representing milder storm conditions form 12 SE each $(1 \times 1$ primary and $3 \times 4$ secondary parameters). Number of SE decreases with the increase of storm severity (i.e. magnitude of hydraulic parameters) on the account of lesser combination of secondary parameters figured. Thus, in the last three rows in Table 1 , we have only 3 SE per pair $-1 \times 1$ primary and $1\left(100^{\circ} \div 110^{\circ}\right) \times 3(6,10$, $16 \mathrm{~h})$ secondary parameters. This choice is based on knowledge about the system's high-energy states (only storms hitting from that directional bin and lasting that amount of time can produce surge levels and wave heights of similar magnitude) and aims at optimization of the BN training process. In order to run the process-based model, those synthetic time series describing the coastal system states are imposed at the seaward boundary of the model grid at $15 \mathrm{~m}$ depth. 
Several alternatives involving DRR measures were examined both in present and projected conditions. In order to be able to compare them with a situation where no DRR measures are implemented, a so called 'zero-alternative' (A0) is suggested. The alternatives are listed in Table 2 together with other relevant information.

\begin{tabular}{|c|c|c|c|}
\hline Alternative & Event type/Scenario & Number of simulations & DRR measures \\
\hline $\mathrm{A} 0$ & SE/P & 230 & - \\
\hline A1 & SE/P & 230 & DRR1 \\
\hline A2 & SE/P & 230 & DRR2 \\
\hline A3 & SE/CC & 245 & - \\
\hline A4 & SE/CC & 245 & DRR1 \\
\hline A5 & SE/CC & 245 & DRR2 \\
\hline
\end{tabular}

690 simulations were performed for present conditions, while the number of those regarding the selected CC scenario RCP8.5 2060 amounted to 735 , to form a total number of 1425 simulations.

\section{BN structure}

Bayesian Network, that was setup for Varna hotspot, consists of 16 nodes (Fig. 7). Three of them relate to hydraulic boundary conditions $-\mathrm{h}, \mathrm{H}_{\mathrm{s}}$ and sea level rise (SLR) - each including three, six and two bins, respectively, as the latter is a deterministic one making distinction between present (0) and projected (1) conditions. Another four nodes relate to receptors spread across the three areas as described above.

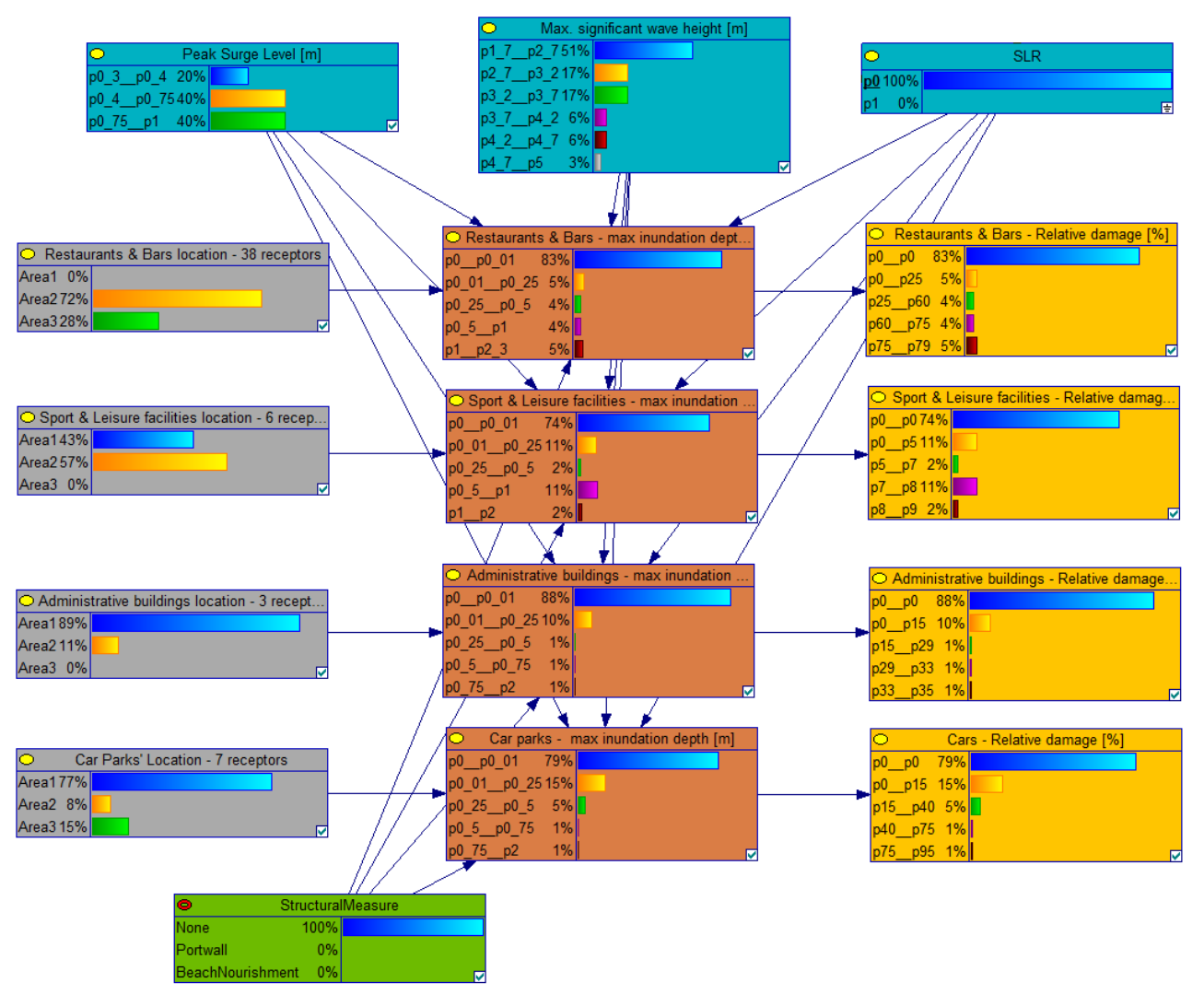

Figure 7. Overall layout of the Bayesian Network showing nodes and their dependence. The example presents evaluation of hazard and impact relevant for 'zero-alternative', i.e. the system state in present climate conditions with no DRR measures implemented. 
The hazard and impact variables are presented by four nodes each - one per receptor group. The XBeach model output chosen to quantify flooding hazard is maximum inundation depth (hhmax), while the impact is expressed as relative damage evaluated using the corresponding depth-damage curves. Hazard and impact magnitudes are framed in five bins, which correspond to the levels of vulnerability. DRR measures are presented by one node named 'StructuralMeasure', which allows determining between 'PortWall' and 'BeachNourishment' or 'None' of them.

The boundary conditions, receptors (site geomorphology) and DRR nodes are the parent nodes. The child nodes are the coastal hazard nodes, which in turn are parents to the impact nodes.

In Fig. 7 boundary conditions nodes are depicted as blue boxes on the top, receptors are the grey boxes on the left and the DRR measures node is presented as a green box on the bottom. Brown boxes indicating the hazard nodes are placed in the center, while yellow boxes providing insight on the quantification of impact are on the right.

\section{RESULTS}

In this section, $\mathrm{BN}$ predictions with respects to different alternatives are presented and comparison is done not only between alternatives involving implementation of DRR measures but also those valid for different climate conditions.

As mentioned above, A0 (or 'zero-alternative') sets the basis by addressing current conditions with no DRR measures implemented, which is compared to higher hazard intensities as implied by the CC scenario (A3). The BN prediction is done for the entire hotspot domain and results are presented in Table 3. They show that most affected receptors are sport facilities (R2) followed by restaurants (R1) and car parks (R4). From 9 to $13 \%$ of sport facilities and restaurants can be flooded with more than $0.5 \mathrm{~m}$ water depth that corresponds to more than $60 \%$ damage. Percentage of receptors in risk increases to $15-16 \%$ when accounting for climate change. The respective values for car parks are 7 and $14 \%$. The largest increase $(3 \%)$ of receptors bearing the severest damage $(75 \div 79 \%)$ due to $\mathrm{CC}$ is predicted for sport facilities and restaurants as well. Administrative buildings (R3) are less vulnerable - only $3 \%$ of receptors are predicted to be inundated with water depths higher than $0.25 \mathrm{~m}$ (i.e. suffer more than $15 \%$ damage) and this is not projected to increase in the future.

A1 is defined by a hazard influencing DRR measure (DRR1: Enforced embankment of port wall). The effect of this measure is most important in Area 1; therefore, presented results are relevant for that area, in which there are no restaurants (Table 4). Predictions suggest that sport and leisure facilities are most affected by flooding hazard. As a results of DRR1 implementation, BN predicts a higher percentage of car parks falling into the safe hazard/damage bin(s) (87\%) compared to A0 (79\%) (Table 3 ). However, considering climate change, it drops to $76 \%$. Moreover, doubles the percentage (from 4 to $8 \%$ ) of cars suffering damage higher than $15 \%$. The CC influence is smaller for R2 as only $4 \%$ of receptors would bear severe impact (60-79\% damage). As for administrative buildings, they appear to be the least vulnerable receptor.

Next alternative in focus, A2, considers another hazard influencing DRR measure (DRR2: Beach nourishment), which effect is most prominent in Area 2; therefore, the summary table (Table 5) shows results for this area. Administrative buildings and car parks are almost not affected by flooding as they are located in the southern part (the wider one) of the beach or along the promenade backing the beach, which makes them less exposed. This explains the reason BN predicts no change of relative damage neither in case of application of the structural measure, nor with respect to climate change.

However, DRR2 proved to be very effective with respect to other two receptors: percentage of restaurants flooded with more than $0.5 \mathrm{~m}$ water depth decreased from $9 \%$ (A0) to only $2 \%$, whilst for sport facilities this decrease is even more pronounced - from 13 to $2 \%$. The effect of this measure is quite feasible also with respect to $\mathrm{CC}$ as above percentage increase with less than $2 \%$ together with a more pronounced decrease of completely safe receptors with about 4 to $9 \%$.

\section{DISCUSSION AND CONCLUSIONS}

The presented study was performed to prove the ability of a Bayesian Network to serve as a tool for impact assessment of marine storm related hazards and to test the effect of disaster risk reduction measures designed for Varna hotspot, which represents an open bay comprising variety of coast types and occupation. The XBeach model was used to simulate flooding hazard resulting from synthetic events of variable intensity for both present and climate change scenarios. To this end, several alternatives were proposed covering a range of solutions such as reinforcement of port wall (A1-A4) and beach nourishment (A2-A5), including as well the 'zero-alternative' (A0-A3). 


\begin{tabular}{|c|c|c|c|c|c|}
\hline \multicolumn{2}{|c|}{ Bins } & \multicolumn{2}{|c|}{ A0 } & \multicolumn{2}{|c|}{ A3 } \\
\hline $\mathrm{H}[\mathrm{m}]$ & RD [\%] & H_R1 [\%] & RD_R1 [\%] & H_R1 [\%] & RD_R1 [\%] \\
\hline $0 \div 0.01$ & 0 & 83 & 83 & $80^{\circ}$ & 80 \\
\hline $0.01 \div 0.25$ & $0 \div 25$ & 5 & 5 & 5 & 5 \\
\hline $0.25 \div 0.5$ & $25 \div 60$ & 4 & 4 & 4 & 4 \\
\hline $0.5 \div 1.0$ & $60 \div 75$ & 4 & 4 & 3 & 3 \\
\hline $1.0 \div 2.0$ & $75 \div 79$ & 5 & 5 & 8 & 8 \\
\hline & & H_R2 [\%] & RD_R2 [\%] & H_R2 [\%] & RD_R2 [\%] \\
\hline $0 \div 0.01$ & 0 & -74 & 74 & 72 & 72 \\
\hline $0.01 \div 0.25$ & $0 \div 5$ & 11 & 11 & 12 & 12 \\
\hline $0.25 \div 0.5$ & $5 \div 7$ & 2 & 2 & 2 & 2 \\
\hline $0.5 \div 1.0$ & $7 \div 8$ & 11 & 11 & 9 & 9 \\
\hline $1.0 \div 2.0$ & $8 \div 9$ & 2 & 2 & 5 & 5 \\
\hline & & H_R3 [\%] & RD_R3 [\%] & H_R3 [\%] & RD_R3 [\%] \\
\hline $0 \div 0.01$ & 0 & 88 & 88 & 86 & 86 \\
\hline $0.01 \div 0.25$ & $0 \div 15$ & 10 & 10 & 11 & 11 \\
\hline $0.25 \div 0.5$ & $15 \div 29$ & 1 & 1 & 1 & 1 \\
\hline $0.5 \div 0.75$ & $29 \div 33$ & 1 & 1 & 1 & 1 \\
\hline $0.75 \div 2.0$ & $33 \div 35$ & 1 & 1 & 1 & 1 \\
\hline & & H_R4 [\%] & RD_R4 [\%] & H_R4 [\%] & RD_R4 [\%] \\
\hline $0 \div 0.01$ & 0 & $79^{\circ}$ & 79 & $68^{\circ}$ & 68 \\
\hline $0.01 \div 0.25$ & $0 \div 15$ & 15 & 15 & 20 & 20 \\
\hline $0.25 \div 0.5$ & $15 \div 40$ & 5 & 5 & 11 & 11 \\
\hline $0.5 \div 0.75$ & $40 \div 75$ & 1 & 1 & 1 & 1 \\
\hline $0.75 \div 2.0$ & $75 \div 95$ & 1 & 1 & 1 & 1 \\
\hline
\end{tabular}

\begin{tabular}{|cc|cc|cc|}
\hline \multicolumn{6}{|c|}{ Table 4. Summary table for A1 vs. A4. } \\
\hline Bins & RD [\%] & H_R2 [\%] & RD_R2 [\%] & H_R2 [\%] & RD_R2 [\%] \\
\hline $\mathrm{H}[\mathrm{m}]$ & 0 & 77 & 77 & 73 & 73 \\
$0 \div 0.01$ & 0 & 20 & 20 & 23 & 23 \\
$0.01 \div 0.25$ & $0 \div 5$ & 1 & 1 & 2 & 2 \\
$0.25 \div 0.5$ & $5 \div 7$ & 1 & 1 & 1 & 1 \\
$0.5 \div 1.0$ & $7 \div 8$ & 1 & 1 & 1 & 1 \\
$1.0 \div 2.0$ & $8 \div 9$ & H_R3 [\%] & RD_R3 [\%] & H_R3 [\%] & RD_R3 [\%] \\
$0 \div 0.01$ & 0 & 95 & 95 & 90 & 90 \\
$0.01 \div 0.25$ & $0 \div 15$ & 2 & 2 & 4 & 4 \\
$0.25 \div 0.5$ & $15 \div 29$ & 1 & 1 & 3 & 3 \\
$0.5 \div 0.75$ & $29 \div 33$ & 1 & 1 & 2 & 2 \\
$0.75 \div 2.0$ & $33 \div 35$ & 1 & 1 & 1 & 1 \\
\hline & & H_R4 [\%] & RD_R4 [\%] & H_R4 [\%] & RD_R4 [\%] \\
$0 \div 0.01$ & 0 & 87 & 87 & 76 & 76 \\
$0.01 \div 0.25$ & $0 \div 15$ & 9 & 9 & 16 & 16 \\
$0.25 \div 0.5$ & $15 \div 40$ & 2 & 2 & 6 & 6 \\
$0.5 \div 0.75$ & $40 \div 75$ & 1 & 1 & 1 & 1 \\
$0.75 \div 2.0$ & $75 \div 95$ & 1 & 1 & 1 & 1 \\
\hline
\end{tabular}

\begin{tabular}{|c|c|c|c|c|c|}
\hline \multicolumn{6}{|c|}{ Table 5. Summary table for A2 vs. A5. } \\
\hline \multicolumn{2}{|c|}{ Bins } & \multicolumn{2}{|c|}{ A2 } & \multicolumn{2}{|c|}{ A5 } \\
\hline $\mathrm{H}[\mathrm{m}]$ & RD [\%] & H_R1 [\%] & RD_R1 [\%] & H_R1 [\%] & RD_R1 [\%] \\
\hline $0 \div 0.01$ & 0 & 93 & 93 & 84 & 84 \\
\hline $0.01 \div 0.25$ & $0 \div 25$ & 4 & 4 & 12 & 12 \\
\hline $0.25 \div 0.5$ & $25 \div 60$ & 1 & 1 & 3 & 3 \\
\hline $0.5 \div 1.0$ & $60 \div 75$ & 1 & 1 & 1 & 1 \\
\hline $1.0 \div 2.0$ & $75 \div 79$ & 1 & 1 & 0 & 0 \\
\hline & & H_R2 [\%] & RD_R2 [\%] & H_R2 [\%] & RD_R2 [\%] \\
\hline $0 \div 0.01$ & 0 & 95 & 95 & 91 & 91 \\
\hline $0.01 \div 0.25$ & $0 \div 5$ & 2 & 2 & 3 & 3 \\
\hline $0.25 \div 0.5$ & $5 \div 7$ & 1 & 1 & 2 & 2 \\
\hline $0.5 \div 1.0$ & $7 \div 8$ & 1 & 1 & 4 & 4 \\
\hline $1.0 \div 2.0$ & $8 \div 9$ & 1 & 1 & 0 & 0 \\
\hline & & H_R4 [\%] & RD_R4 [\%] & H_R4 [\%] & RD_R4 [\%] \\
\hline $0 \div 0.01$ & 0 & 96 & 96 & 96 & 96 \\
\hline $0.01 \div 0.25$ & $0 \div 15$ & 1 & 1 & 1 & 1 \\
\hline $0.25 \div 0.5$ & $15 \div 40$ & 1 & 1 & 1 & 1 \\
\hline $0.5 \div 0.75$ & $40 \div 75$ & 1 & 1 & 1 & 1 \\
\hline $0.75 \div 2.0$ & $75 \div 95$ & 1 & 1 & 1 & 1 \\
\hline
\end{tabular}


In present conditions (A0), flooding poses a threat to $18 \%$ of restaurants, $26 \%$ of sport facilities and $22 \%$ of car parks, while administrative buildings are less vulnerable $(13 \%)$. As a whole, climate change does not contribute to a considerable increase of the receptors' vulnerability.

The first hazard influencing DRR measure proved to be effective in present conditions as overtopping of the port wall ceases to be a major problem but the situation alters for climate change scenario. This clearly indicates there is a time window of a couple of decades during which more reliable solutions should be sought and implemented.

The second hazard influencing DRR measure turned to be quite effective for all receptors since after its implementation the percentage of safe restaurants, sport facilities and car parks increased by $10 \%, 11 \%$ and $17 \%$, respectively. Moreover, this measure is quite sustainable as it retains its effectiveness even in consideration of climate change. It has to be borne in mind though that this measure should be maintained on a regular basis in order to function properly.

The accuracy of results depends on different factors such as input data for the models, capabilities of model itself, BN configuration, number of simulations performed, quality of depth-damage curves etc.

Previous studies have shown that the uncertainties introduced by the ocean models are small compared to the ones related to the accuracy and resolution of the atmospheric forcing (e.g., Jordà et al., 2012). In this sense, it is possible that wave boundary data had been slightly underestimated as the wave hindcasting, used to define the limits of wave properties' variability, was driven with not very high resolution wind data. Surge and sea level boundary data for both historic and projected conditions are deemed accurate enough. The effect of potential limitations on data quality was considered not critical since the study, which these data originate from, focuses on assessing relative changes in extreme sea levels, rather than presenting accurate predictions or operational forecasts. Thus, the relative accuracy of the absolute sea level values should be considered in the 10-20\% range (Vousdoukas et al. 2016). Further concerning boundary conditions, as simulations are run entirely for SE, this could have been altered slightly the storm pattern potentially leading to underestimation of hazard intensity.

Input topography data for model bed originating from orthophoto images are of high resolution ( $0.5 \mathrm{~m}$ horizontal and $10 \mathrm{~cm}$ vertical) and cannot be considered as source of uncertainty in terms of both hazard modeling and receptors mapping. Beach face topography and shallow bathymetry data could be an issue but for this type of prediction they are considered accurate enough.

As for the onshore hazard modeling, it has been found that XBeach tend to underpredict wave runups (Valchev et al. 2107). This problem is connected with the 'surfbeat' mode, in which the model was implemented. This mode resolves only the long-wave run-up that could be an issue if the wave field propagating at the off-shore model boundary is short-crested. Furthermore, 'surfbeat' mode is more suitable for dissipative slopes as those in the northern part of Varna beach; however, on steeper slopes, as those in the central and south beach, the contribution of the short waves run-up may gain importance resulting in underprediction of the run-ups. Number of simulations covering wide range and hydraulic boundary conditions is considered sufficient for a reliable BN training.

Moreover, problems with model performance and hazard mapping are also related to the grid design since it is quite difficult to represent the complex coastal configuration within the hotspot in equal details, all the more that, the grid resolution should be compatible with the computational efficacy.

Finally, among all factors defining the accuracy of the impact assessment, the most important one is the feasibility of the depth-damage curves. In this sense, the use of available susceptibility curves seems problematic since they do not represent the vulnerability to coastal flooding. Nevertheless, being the only source accessible, it is believed their use does not distort the overall picture and suits well the requirements of the current assessment.

The analysis of the model simulations through the prism of the BN provides a useful insight of the problems at the study site. They are in agreement with the historical evidence of storm impacts. Still, the use of SE approach can contribute to filling the knowledge gap with respect to hazard intensity and more importantly to the expected coastal impact. The overall conclusion is that the Bayesian Network approach has a great potential for reliable coastal impact prediction.

\section{ACKNOWLEDGMENTS}

This work was supported by the European Community's 7th Framework Programme through the grant to RISC-KIT (Resilience-increasing Strategies for Coasts - Toolkit), contract no. 603458, Fund 
for Scientific Research affiliated to Ministry of Education and Science, Bulgaria, contract Д01-188, and contributions by partner institutes.

\section{REFERENCES}

Andreeva, N., N. Valchev, E. Trifonova, P. Eftimova, D. Kirilova and M Georgieva. 2011. Literary review of historical storm events in the western Black Sea. Proc. of Union of Scientists - Varna, "Marine sciences", 105-112 (In Bulgarian).

Bertin, X., K. Lia, A. Roland, Y.J. Zhang, J.F. Breilh and E. Chaumillon. 2014. A modeling-based analysis of the flooding associated with Xynthia, central Bay of Biscay, Coastal Engineering, 94, 80-89.

Collet, I. and A. Engelbert. 2013. Coastal regions: people living along the coastline, integration of NUTS 2010 and latest population grid, EUROSTAT.

Dean, R.G. 1977. Equilibrium beach profiles: U.S. Atlantic and Gulf coasts, Department of Civil Engineering, Ocean Engineering Report No. 12, University of Delaware, Newark, DE.

Dean, R.G., D.L Kriebel and T.L. Walton. 2008. Cross-Shore Sediment Transport Processes, in: D. King (editor), Coastal Engineering Manual, Part III, Coastal Sediment Processes, Chapter II-2, Engineer Manual 1110-2-1100, U.S. Army Corps of Engineers, Washington, DC.

Dimitrov, D., I. Nyagolov, S. Balabanova, N. Lisev, G. Koshinchanov, A. Korcheva, Y. Marinski, L. Pashova, D. Grozdev, V. Vasilev, B. Bozhilov and N. Tsvetkova. 2013. Methods for assessment of flood hazard and flood risk, according to requirements of the EU Floods Directive 2007/60: Final Report, Black Sea Basin Directorate, Contract No D-30-62, 357 pp. (In Bulgarian)

Eftimova, P., E. Trifonova, N. Valchev and N. Andreeva. 2012. Beach erosion caused by storms. Morphological model set up and calibration, Proceedings of $11^{\text {th }}$ Int. Conf. on Marine Sciences and technologies, Black Sea'2012, 69-73.

Hallegatte, S., C. Green, R. J. Nicholls and J. Corfee-Morlot. 2013. Future flood losses in major coastal cities, Nature Climate Change, 3(9), 802-806.

Jaeger, W.S., E. Christie, A.M. Hanea, C. den Heijera and T. Spencer. 2017. Decision support for coastal risk management: a Bayesian Network approach, Coastal Enginering (submitted)

Jordà, G., D. Gomis, E. Álvarez-Fanjul and S. Somot. 2012. Atmospheric contribution to Mediterranean and nearby Atlantic sea level variability under different climate change scenarios, Global and Planetary Change, 80-81, 198-214.

Kunz, M., B. Mühr, T. Kunz-Plapp, J. E. Daniell, B. Khazai, F. Wenzel, M. Vannieuwenhuyse, T. Comes, F. Elmer, K. Schröter, J. Fohringer, T. Münzberg, C. Lucas and J. Zschau. 2013. Investigation of superstorm Sandy 2012 in a multi-disciplinary approach, Nat. Hazards Earth Syst. Sci., 13, 2579-2598

Lindemer, C.A., N.G. Plant, J.A. Puleo, D.M. Thompson and T.V. Wamsley. 2010. Numerical simulation of a low-lying barrier island's morphological response to Hurricane Katrina, Coastal Engineering, 57, 985-995.

McCall, R.T., J.S.M. van Thiel de Vries, N.G. Plant, A.R. van Dongeren, J.A. Roelvink, D.M. Thompson and A.J.H.M. Reniers. 2010. Two-dimensional time dependent hurricane overwash and erosion modeling at Santa Rosa Island, Coastal Engineering, 57, 668-683.

Moss, R., M. Babiker, S. Brinkma, E. Calvo, T. Carter, J. Edmonds, I. Elgizouli, S. Emori, L. Erda, K. Hibbard, R. Jones, M. Kainuma, J. Kelleher, J. F. Lamarque, M. Manning, B. Matthews, J. Meehl, L. Meyer, J. Mitchell, N. Nakicenovic, B. O’Neill, R. Pichs, K. Riahi, S. Rose, P. Runci, R. Stouffer, D. van Vuuren, J. Weyant, T. Wilbanks, J. P. van Ypersele and M. Zurek. 2008. Towards New Scenarios for Analysis of Emissions, Climate Change, Impacts, and Response Strategies. Geneva: Intergovernmental Panel on Climate Change, $132 \mathrm{pp}$.

National Statistical Institute (NSI). 2011. 2011 Population Census in the Republic of Bulgaria (final data), 2011, 51 pp. (URL: 〈www.nsi.bg/census2011/PDOCS2/Census2011 finalen.pdf〉).

Pearl, J. and S. Russel. 1988. Bayesian Networks. University of California, http://dx.doi.org/10.1145/1859204.1859227.

Roelvink, D., A. Reniers, A. van Dongeren, J. van Thiel de Vries, R. McCall and J. Lescinski. 2009. Modelling storm impacts on beaches, dunes and barrier islands. Coastal Engineering, 56, 11331152.

Stakev, M. 1980. About the break-down state of some coastal structures after the storm in February 1979. Shipbuilding and Navigation, 10, 26-30 (in Bulgarian). 
Trifonova, E., N. Valchev, N. Andreeva and P. Eftimova. 2012. Critical storm thresholds for morphological changes in the western Black Sea coastal zone, Geomorphology, 143-144, 81-94.

Valchev, N., E. Trifonova and N. Andreeva. 2012. Past and recent trends in the western Black Sea storminess, Nat. Hazards Earth Syst. Sci., 12, 1-17.

Valchev, N., N. Andreeva, P. Eftimova, B. Prodanov and I. Kotsev. 2016. Assessment of vulnerability to storm induced flood hazard along diverse coastline settings, Proceedings of 3rd European Conf. on Flood Risk Management, FLOODrisk 2016, E3S Web of Conferences 710002.

Valchev, N., P. Eftimova and N. Andreeva. 2017. Implementation and validation of a multi-domain coastal hazard forecasting system in an open bay, Coastal Engineering (submitted)

Van Dongeren, A., P. Ciavola, G. Martinez, C. Viavattene, S. DeKleermaeker, O. Ferreira, C. Costa and R. McCall. 2016. RISC-KIT: Resilience-increasing Strategies for Coasts, Proceedings of 3rd European Conf. on Flood Risk Management, FLOODrisk 2016, E3S Web of Conferences 717001

Van Thiel de Vries, J.S.M. 2009. Dune Erosion during Storm Surges. Delft Univesity of Technology

Vousdoukas, M.I., E. Voukouvalas, A. Annunziato, A. Giardino and L. Feyen. 2016. Projections of extreme storm surge levels along Europe, Climate Dynamics, 47(9), 1-20.

West, M. and J. Harrison. 1997. Bayesian forecasting and dynamic models, Springer, 694 pp. 